\title{
Natural Convection of Non-Newtonian Fluids in a Square Cavity with a Localized Heat Source
}

\author{
Afrasiab Raisi \\ Shahrekord University, Faculty of Engineering, Iran
}

This study investigates the natural convection cooling of a heat source placed on the bottom of a cavity filled with non-Newtonian power-law fluids. The heat source produces a uniform heat flux. The remaining parts of the bottom wall of the cavity are insulated, and the vertical, and top walls are kept at a low temperature. The governing equations for the power-law fluid flow are solved with the numerical finite difference method based on the control volume formulation and SIMPLE algorithm. The study investigates the effects of relevant parameters such as the Rayleigh number, the power-law index and the heat source length and heat source location on the thermal performance of the cavity. The results show that as the Rayleigh number increases, particularly when $n<1$, the thermal performance of the cavity is improved. Furthermore, using non-Newtonian shear thinning fluids, especially at higher Rayleigh numbers, improves the cooling performance of the heat source. The results also show that, depending on the Rayleigh number and the power-law index, the length and position of the heat source have significant effects on the thermal performance of the cavity.

Keywords: natural convection, cavity, heat source, non-Newtonian, power-law

Highlights

- $\quad$ The numerical simulation of natural convection of non-Newtonian power-law fluids.

- $\quad$ The thermal performance of an enclosure filled with a non-Newtonian fluid.

- $\quad$ The thermal performance of the enclosure is enhanced as the Rayleigh number increases.

- $\quad$ The average Nusselt number increases for shear-thinning and reduces for shear-thickening fluids compared to Newtonian fluids.

\section{O INTRODUCTION}

Natural convection is often considered to be the main mechanism of heat transfer in cavities. It has a variety of applications in many engineering systems. The fluid inside the cavity can occasionally be regarded as Newtonian; however, in many natural or artificial systems, this fluid has a non-Newtonian behaviour. With their important applications in engineering, fluids such as nanofluids, molten polymers, paints, food stuff, inks, organic matter, and glues may all exhibit strong non-Newtonian behaviours. Examining natural convection in non-Newtonian fluids in cavities is, therefore, highly crucial to engineering and has many applications in it. Food processing, oil drilling, polymer engineering, geophysical systems, electronic cooling systems, and nuclear reactors are examples of natural convection in non-Newtonian fluids. Natural convection in Newtonian fluids has been extensively studied in cavities under various boundary conditions. Catton [1] examined natural convection in vertical, horizontal and tilted rectangular enclosures. Davis [2] studied natural convection inside an enclosure with isothermal sidewalls and adiabatic horizontal walls. A comprehensive study of natural convection literature was done by Ostrach [3]. The applications of natural convection were presented by Bejan [4] and Emery and Lee [5]. Aydin [6] assessed natural convection inside a rectangular enclosure, which was heated from the left vertical wall and was cooled from the top wall; the other two walls were adiabatic. The thermal performance of rectangular enclosures is dependent on the aspect ratio of the enclosures [7]. The conducted studies on the natural convection field have been reviewed by Ganguli et al. [8]. Arpino et al. [9] analysed transient natural convection in tall cavities. They used a dual time-stepping to improve the transient solution. In another study, Arpino et al. [10] numerically studied transient natural convection in porous and partially porous cavities with an emphasis on the dependence of flow behaviour on Ra, porous layer permeability, and cavity aspect ratio [1] to [10].

Ozoe and Churchill [11] were perhaps the first to study forced convection in non-Newtonian fluids in cavities. They investigated natural convection in two non-Newtonian fluids, i.e. Ostwald-de Waele (powerlaw) and Ellis, in a shallow horizontal cavity heated from the bottom and cooled from above. They found that the critical value of Rayleigh number for the onset of natural convection increases with the fluid index. Cavities with natural convection are divided into two general groups. The first group includes cavities that are heated and cooled from the side walls, and the 
second group includes cavities that are heated from the bottom. In the second group, natural convection begins when the Rayleigh number exceeds a critical value.

Kaddiry et al. [12] conducted a numerical investigation of a Rayleigh- Benard convection of a non-Newtonian power-law fluid in a square cavity. They showed that the critical value of the Rayleigh number for onset natural convection was an increasing function of the power-law index. For example, the results indicated that $R a_{c} \approx 600$ for $n=0.6$ and $R a_{c} \approx 5000$ for $n=1.4$.

Kim et al. [13] studied transient natural convection in non-Newtonian power-law fluids in a vertical cavity by assuming the horizontal walls to be insulated and taking the cause of the buoyancy force and natural convection inside the cavity to be the simultaneous temperature change at the vertical walls. They found that, at a certain value of the Rayleigh number, both the convection strength and the heat transfer rate change for non-Newtonian fluids in comparison to Newtonian fluids, so that they are both increased at $n<1$ and reduced at $n>1$. Lamsaadi et al. [14] studied transient natural convection in non-Newtonian powerlaw fluids in a shallow cavity using numerical and analytical methods. Their cavity consisted of long, insulated, horizontal walls and short vertical walls, with the vertical walls heated and cooled with a constant heat flux. The results of their study showed that heat transfer and flow characteristics were not sensitive to an increase in the Prandtl number or the aspect ratio of the cavity, given that the parameters were sufficiently large. They argued that $n$ (the power-law index) and the Rayleigh number were parameters that affected the rate of heat transfer and flow field in shallow cavities with non-Newtonian fluids and large Prandtl numbers. Lamsaadi et al. [15] also investigated steady natural convection in nonNewtonian power-law fluids in a tilted rectangular slit using the numerical method. A constant heat flux was applied to the side walls, and the remaining walls were insulated. This study was conducted within the Rayleigh number range of $10 \leq R a \leq 10^{5}$, the powerlaw index of $0.6 \leq n \leq 1.4$ and the rotation angle of $-180^{\circ} \leq \Phi \leq 180^{\circ}$. They found that given a certain value of Rayleigh number, the rotation of the cavity had a dramatic effect on the rate of heat transfer. The highest rate of heat transfer occurred when the cavity was heated from the bottom, and the effect of the cavity rotation increased as the value of $n$ decreased.

Several studies have recently investigated natural convection in non-Newtonian fluids in square and rectangular cavities with horizontal insulated walls and vertical walls with constant temperatures. Turan et al. [16] used the FLUENT ANSYS commercial package to simulate power-law fluids. Ternik and Rudolf [17] investigated the natural convection of a non-Newtonian nanofluid in an enclosure with isothermal sidewalls and adiabatic horizontal walls. The natural convection of power-law fluids has been assessed in a rectangular enclosure [18] and in a square enclosure [19] with isothermal vertical walls. The common findings of these studies showed that the heat transfer and flow field were affected by the Rayleigh number and $n$ (the power-law index). However, for any given $n$ and $R a$, the average Nusselt number was not affected by the Prandtl number. Moreover, for rectangular cavities with a boundary condition of a constant temperature on the vertical walls, the Nusselt number did not vary uniformly as the aspect ratio increased; however, when the boundary condition was a constant heat flux applied to the vertical walls, this variation was uniform.

Alloui [20] studied natural convection in a non-Newtonian fluid in a vertical cavity using the Carreau-Yasuda model and showed that compared to Newtonian fluids, the rate of heat transfer and convection strength increased when $n<1$ and decreased when $n>1$. The changes in the $n$ value did not greatly affect the rate of heat transfer when the Rayleigh number was small.

Natural convection in non-Newtonian fluids in cavities heated from the bottom has received less attention in literature than the studies considering cavities heated from the sides. Lamsaadi et al. [21] studied natural convection in a horizontal cavity heated from the bottom and cooled from above using numerical and analytical methods. They showed that fluid flow, temperature distribution and the rate of heat transfer were sensitive to $n$ (the power-law index); however, for large Prandtl numbers, they were no longer sensitive to the Prandtl number. Compared to Newtonian fluids, non-Newtonian fluids were associated with the onset of natural convection by a single cell flow when $n<1$ and behaved inversely when $n>1$.

Ouertatani et al. [22] conducted a numerical assessment of Rayleigh-Bénard convection in a rectangular cavity; they considered a cavity with the bottom wall at a constant temperature of $T_{h}$ and the top wall at a constant temperature of $T_{c}$. They assumed the vertical walls to be insulated. Their study yielded streamlines and isotherms for the Rayleigh numbers in the range of $10^{4} \leq R a \leq 10^{6}$. They argued that the rate of heat transfer increased with the Rayleigh number. 
Mahrood Khadangi et al. [23] conducted an experimental study of natural convection of a nonNewtonian nanofluid in a cavity heated from the bottom with a constant heat flux and cooled from above. They used the $\mathrm{Al}_{2} \mathrm{O}_{3}$ and $\mathrm{TiO}_{2}$ nanoparticles and a 0.5 weight percent solution of carboxymethyl cellulose as the base fluid for the nanofluid. The results of their study showed improvements in the rate of heat transfer of natural convection in non-Newtonian nanofluids at low concentrations of nanoparticles. However, the rate of heat transfer began to decline as the volume percent of nanoparticles exceeded a certain amount.

Khazzar et al. [24] conducted a numerical study of natural convection in a non-Newtonian power-law fluid in a tilted rectangular cavity heated from the bottom and cooled from above. They conducted this study for different tilt angles of the cavity $(0 \leq \varphi \leq 90)$ and calculated the rate of heat transfer and flow field for different aspect ratios, Rayleigh numbers and power-law indices. Their results showed an increasing and a decreasing average Nusselt number for nonNewtonian shear-thinning $(n<1)$ and non-Newtonian shear-thickening $(n>1)$ fluids, in respective order. The increase and decrease in the average Nusselt number depended on the Rayleigh number, the Prandtl number, the aspect ratio, and the power-law index.

Alloui et al. [25] conducted a numerical and analytical investigation on the onset of natural convection in a shallow rectangular cavity filled with power-law fluids. The cavity was heated from the bottom through a constant heat flux. They calculated the critical value of the Rayleigh number for non-Newtonian fluids given $n>1$ and $n<1$ using the linear stability theory. Turan et al. [26] conducted a numerical study of a laminar natural convection of power-law fluids in a square cavity heated from the bottom through a constant heat flux. They argued that the average Nusselt number was significantly affected by the Rayleigh number and $n$ (the power-law index); however, it was not affected significantly by the Prandtl number. They also compared bottom-heated and side-heated cavities and concluded that for shear-thinning fluids and at high Rayleigh numbers, the average Nusselt number was higher for side-heated cavities in comparison to bottom-heated ones. However, for shear-thickening and Newtonian fluids, the Nusselt number remained approximately the same for both side-heated and bottom-heated cavities.

Yigit et al. [27] studied the effects of aspect ratio on natural convection in non-Newtonian Bingham fluids in bottom-heated and top-cooled rectangular cavities. They varied the aspect ratio in the range of $(0.25 \leq A R \leq 4)$ and the Rayleigh number in the range of $10^{3} \leq R a \leq 10^{5}$ while assuming the Prandtl number was constant and equal to 500 . They found that the convection heat transfer was enhanced with an increased Rayleigh number, but that the average Nusselt number was lower in Bingham fluids in comparison to in Newtonian fluids due to an increased yield stress viscosity.

The natural convection of a non-Newtonian power-law fluid was numerically studied by Vinogradov et al. in an inclined cavity [28]. They found that for square-shaped cavities $(A R=1)$, the heat transfer rate in the horizontal position is substantially lower than the heat transfer rate in the vertical $90^{\circ}$ position with the vertical walls conducting. They also indicated that the thermal behaviour of rectangular cavities $(A R>1)$ becomes more complicated due to the formation of the Banard cells.

Despite the valuable studies conducted on the natural convection of non-Newtonian fluids in bottom-heated cavities as shown in the review of the literature, no studies were found on cooling a local heat source placed on the bottom of a cavity by power-law fluids. The heat source in mind can be an electronic device producing heat while operating in an electronic circuit, which requires cooling so as not to exceed a certain permitted temperature. As regards the length of the heat source, as well as the position of its placement on the floor of the cavity, there can be significant effects on the heat transfer and flow of fields; in this study, the effects of the length of the heat source and its position are also reviewed. The present study is, therefore, conducted to examine the effects of parameters such as the Rayleigh number, the powerlaw index and the positioning and length of the heat source on the rate of heat transfer and temperature and flow fields.

\section{METHODS}

\subsection{Governing Equations}

It is assumed that the enclosure is full of a nonNewtonian power-law fluid. The flow is considered to be steady, two-dimensional and laminar, and the radiation effects are negligible. Also, density changes have been modeled in the momentum equation with the Boussinesq approximation. Based on the stated assumptions, the dimensional governing equations of continuity, momentum, and energy are as follows:

$$
\frac{\partial u}{\partial x}+\frac{\partial v}{\partial y}=0
$$




$$
\begin{gathered}
\rho\left(u \frac{\partial u}{\partial x}+v \frac{\partial u}{\partial y}\right)=-\frac{\partial p}{\partial x}+\frac{\partial \tau_{x x}}{\partial x}+\frac{\partial \tau_{x y}}{\partial y}, \\
\rho\left(u \frac{\partial v}{\partial x}+v \frac{\partial v}{\partial y}\right)=-\frac{\partial p}{\partial y}+\frac{\partial \tau_{x y}}{\partial x}+\frac{\partial \tau_{y y}}{\partial y}+\rho g \beta\left(T-T_{c}\right), \\
u \frac{\partial T}{\partial x}+v \frac{\partial T}{\partial y}=\alpha\left(\frac{\partial^{2} T}{\partial x^{2}}+\frac{\partial^{2} T}{\partial y^{2}}\right) .
\end{gathered}
$$

For a non-Newtonian fluid which follows the power-law model the viscous stress tensor is given by [29]:

$$
\tau_{i j}=2 \mu_{a} D_{i j}=\mu_{a}\left(\frac{\partial u_{i}}{\partial x_{j}}+\frac{\partial u_{j}}{\partial x_{i}}\right),
$$

where $D_{i j}$ is the rate of strain tensor for the twodimensional Cartesian coordinate and $\mu_{a}$ is the apparent viscosity that is derived for the twodimensional Cartesian coordinate as:

$$
\mu_{a}=K\left\{2\left[\left(\frac{\partial u}{\partial x}\right)^{2}+\left(\frac{\partial v}{\partial y}\right)^{2}\right]+\left(\frac{\partial v}{\partial x}+\frac{\partial u}{\partial y}\right)^{2}\right\}^{\frac{n-1}{2}}
$$

where $K$ and $n$ are power-law model constants. $K$ is the consistency coefficient and $n$ is the power-law index. Where $(n<1)$, is for shear-thinning fluids and $(n>1)$, is for shear-thickening fluids. When $(n=1)$, a Newtonian fluid is obtained. By using the following non-dimensional parameters:

$$
\begin{gathered}
X=\frac{x}{L}, \quad Y=\frac{y}{L}, \quad U=\frac{u L}{\alpha}, \quad V=\frac{v L}{\alpha}, \\
P=\frac{\bar{p} L^{2}}{\rho \alpha^{2}}, \quad \theta=\frac{T-T_{c}}{\Delta T}, \quad \Delta T=\frac{q^{\prime \prime} L}{k}, \\
R a=\frac{g \beta \Delta T L^{2 n+1}}{\alpha^{n} K / \rho}, \quad P r=\frac{K L^{2 n-2}}{\rho \alpha^{2-n}} .
\end{gathered}
$$

Eqs. (1) to (4) are converted to dimensionless forms, as follows:

$$
\begin{gathered}
\frac{\partial U}{\partial X}+\frac{\partial V}{\partial Y}=0 \\
U \frac{\partial U}{\partial X}+V \frac{\partial U}{\partial Y}=-\frac{\partial P}{\partial X}+ \\
+\operatorname{Pr}\left[2 \frac{\partial}{\partial X}\left(\mu_{a}^{*} \frac{\partial U}{\partial X}\right)+\frac{\partial}{\partial Y}\left(\mu_{a}^{*}\left(\frac{\partial U}{\partial Y}+\frac{\partial V}{\partial X}\right)\right),\right. \\
U \frac{\partial V}{\partial X}+V \frac{\partial V}{\partial Y}=-\frac{\partial P}{\partial Y}+\operatorname{Pr}\left[2 \frac{\partial}{\partial Y}\left(\mu_{a}^{*} \frac{\partial V}{\partial Y}\right)+\right. \\
\left.+\frac{\partial}{\partial X}\left(\mu_{a}^{*}\left(\frac{\partial U}{\partial Y}+\frac{\partial V}{\partial X}\right)\right)\right]+\operatorname{RaPr} \theta
\end{gathered}
$$

$$
U \frac{\partial \theta}{\partial X}+V \frac{\partial \theta}{\partial Y}=\frac{\partial^{2} \theta}{\partial X^{2}}+\frac{\partial^{2} \theta}{\partial Y^{2}},
$$

where $\mu_{a}^{*}$ is the apparent dimensionless viscosity and is defined as:

$$
\mu_{a}^{*}=\left\{2\left[\left(\frac{\partial U}{\partial X}\right)^{2}+\left(\frac{\partial V}{\partial Y}\right)^{2}\right]+\left(\frac{\partial V}{\partial X}+\frac{\partial U}{\partial Y}\right)^{2}\right\}^{\frac{n-1}{2}} .
$$

\subsection{Problem Description}

A schematic diagram of the problem under examination is shown in Fig. 1. The figure illustrates a two-dimensional cavity containing a non-Newtonian power-law fluid. A heat source is placed on the bottom wall of the cavity, producing a uniform heat flux. The remaining parts of the bottom walls are insulated, and the vertical side walls and the top horizontal walls are kept at a relatively low temperature of $T_{c}$. The cavity contains a shear-thinning fluid $(n<1)$, a Newtonian fluid $(n=1)$, and a shear-thickening fluid $(n>1)$. The Prandtl number is assumed constant and equal to 100.

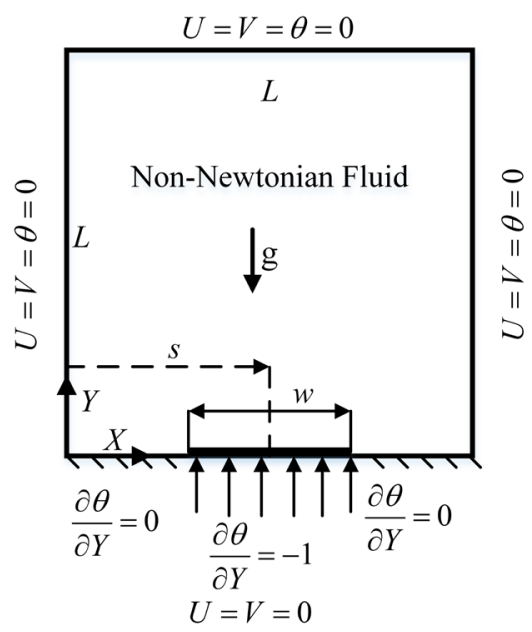

Fig. 1. Schematic diagram of the physical model

According to the schematic diagram of the physical model (Fig. 1), the dimensionless boundary conditions are as follows:

on the left and right walls: $U=V=\theta=0$,

on upper horizontal wall: $U=V=\theta=0$,

on the edges of the lower wall: $U=V=\partial \theta / \partial Y=0$,

on the heat source: $U=V=0$ and $\partial \theta / \partial Y=-1$. (13)

After solving the governing equations numerically, as a measure of the heat transfer rate of the enclosure, the local Nusselt number on the heat source surface can be defined as follows: 


$$
N u=\frac{h L}{k}=\frac{q^{\prime \prime} L}{\left(T_{s}-T_{c}\right) k} .
$$

In Eq. (14), $h$ is the convection heat transfer coefficient. Using the dimensionless parameters, the following relationship is obtained for the local Nusselt number:

$$
N u=\frac{1}{\theta_{s}(X)},
$$

where $\theta_{s}$ is the dimensionless temperature of the heat source. The average Nusselt number can be obtained by integrating the local Nusselt number along the heat source.

$$
N u_{m}=\frac{1}{W} \int_{S-\frac{1}{2} W}^{S+\frac{1}{2} W} \frac{1}{\theta_{S}(X)} d X .
$$

\subsection{Numerical Method, Grid Study and Code Validation}

For obtaining a numerical solution, the governing differential equations have to be converted into algebraic equations. The governing dimensionless equations (Eqs. (8) to (11)) are integrated over each of the finite control volumes in the flow domain; obtained integrated transport equations along with the relevant boundary conditions are discretized by using finite difference method. The convectiondiffusion terms are estimated using the power-law scheme. For obtaining a numerical solution to the discretized equations, SIMPLE algorithm proposed by Patankar [30] is used and a computer program is written in FORTRAN. The convergence criterion is to reduce the maximum mass residual of the grid control volume below $10^{-8}$.

A uniform staggered grid is used for obtaining the numerical solution. The grid independence is examined for $n=0.6, R a=10^{6}, S=0.5$ and $W=0.4$. The results of grid study for three different uniform meshes are presented in Table 1. Using the Richardson extrapolation, the grid-converged value of a general variable such as $\varphi$ is obtained as follows.

$$
\varphi_{\text {ext }}=\varphi_{M 3}-\frac{\varphi_{M 2}-\varphi_{M 3}}{r^{p}-1},
$$

where $\varphi_{M 3}$ is obtained on the basis of the finest grid and $\varphi_{M 2}$ is thus based on the next level of coarse grid, $r=2$ is the ratio between the coarse to fine grid spacing and $p=2$ is the theoretical accuracy.

The results of the grid study show that as the grid points increase from $50 \times 50$ to $200 \times 200$ the error of the numerical solution decreases, and the agreement between the predictions obtained with mesh M2 and extrapolated values is extremely good for both the average Nasselt number and the maximum temperature of the heat source. The grid size $100 \times 100$ is, therefore, used in the numerical solution.

Table 1. Grid independence study $\left(R a=10^{6}, n=0.6, W=0.4\right.$, $S=0.5$ ).

\begin{tabular}{cccccc}
\hline & $N_{x} \times N_{y}$ & $N u_{m}$ & Error [\%] & $\theta_{s, \max }$ & Error [\%] \\
\hline Mesh M1 & $50 \times 50$ & 26.0491 & 1.6 & 0.06431 & 4 \\
\hline Mesh M2 & $100 \times 100$ & 25.7902 & 0.6 & 0.0669 & 0.194 \\
\hline Mesh M3 & $200 \times 200$ & 25.6755 & 0.15 & 0.067 & 0.045 \\
\hline & $\varphi_{\text {ext }}$ & 25.6372 & & 0.06703 & \\
\hline
\end{tabular}

Fig. 2 shows a quarter of the computational grid which is made up of uniform meshes, and Fig. 3 shows the staggered grid in the $x$ direction.

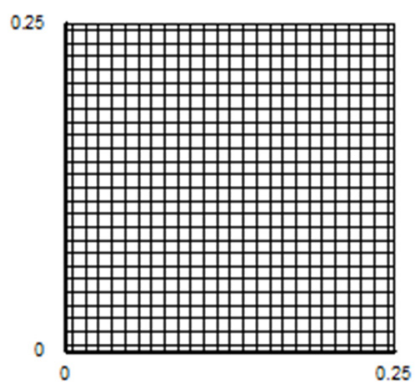

Fig. 2. A quarter of the computational grid

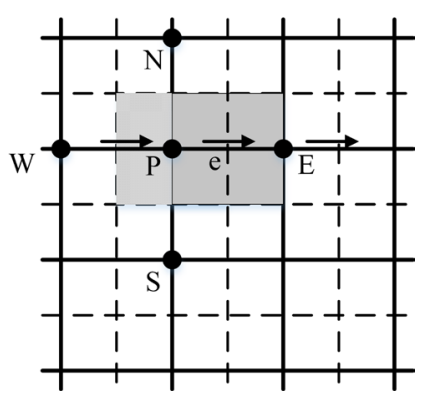

Fig. 3. Staggered grid in the $x$ direction

For validation of the numerical code, the results of the present code are compared with the results obtained by Turan et al. [16]. For this purpose, a square cavity filled with a non-Newtonian power-law fluid is considered, as are insulated horizontal walls, and vertical walls that are at constant and different temperatures of $T_{h}$ and $T_{c}$. The average Nusselt number is calculated for different Rayleigh numbers and power-law indices. Fig. 4 compares the results and shows a good consistency between the results of the present study and of the one by Turan et al. [16]. 


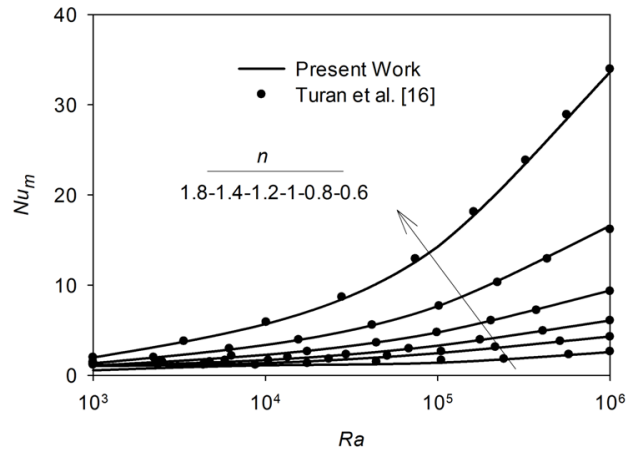

Fig. 4. Validation of the present code against Turan et al. [16]

\section{RESULTS AND DISCUSSION}

The results of the present study are shown in the form of the effects of the Rayleigh number $\left(10^{3} \leq R a \leq 10^{6}\right)$, the power-law index $(0.6 \leq n \leq 1.8)$, the heat source length $(0.2 \leq W \leq 0.8)$ and the heat source position $(0.2 \leq S \leq 0.5)$ on the flow and temperature fields and the rate of heat transfer excreted from the heat source. The Prandtl number is assumed to be 100 throughout the study.

\subsection{Effect of the Rayleigh number and power-law index}

In this part of the study, the effects of the $R a$ and $n$ on the flow and temperature fields and the rate of heat transfer are examined. The length and the position of the heat source are constant, $T_{c}$.

Figs. 5 and 6 show the streamlines and isotherms for different Rayleigh numbers at three different power-law indices $(n=0.6,1,1.8)$. According to Fig. 5 , for all values of the Rayleigh number and the power-law index, two symmetrical counter-rotating cells are formed inside the cavity. For a given value of $n$, the strength of the rotating cells increases with an increase in the Rayleigh number. Due to the reduction in the apparent viscosity of shear-thinning fluids compared to Newtonian fluids, the greatest increase in convection strength occurred at $n=0.6$. Fig. 5 also shows that, for a given Rayleigh number, an increase in $n$ leads to an increase in apparent viscosity and a decrease in the strength of the rotating cells. However, given that poor convection is created inside the cavity at $R a=10^{3}$, increasing the power-law index has no significant effect on the flow field. However, at higher Rayleigh numbers, natural convection inside the cavity becomes stronger, and an increased $n$ then reduces the strength of the rotating cells considerably.

According to Fig. 6, at $R a=10^{3}, 10^{4}$, the form of the isotherm lines implies the dominance of the

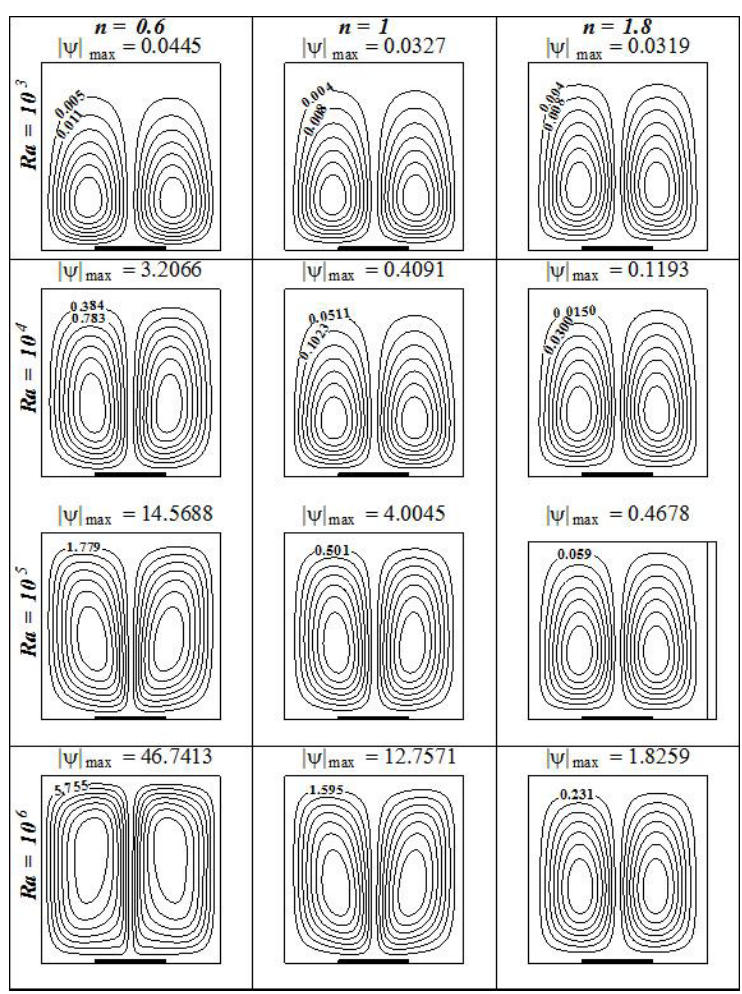

Fig. 5. Streamlines at different Rayleigh numbers and power-law indexes $(W=0.4, S=0.5, \operatorname{Pr}=100)$

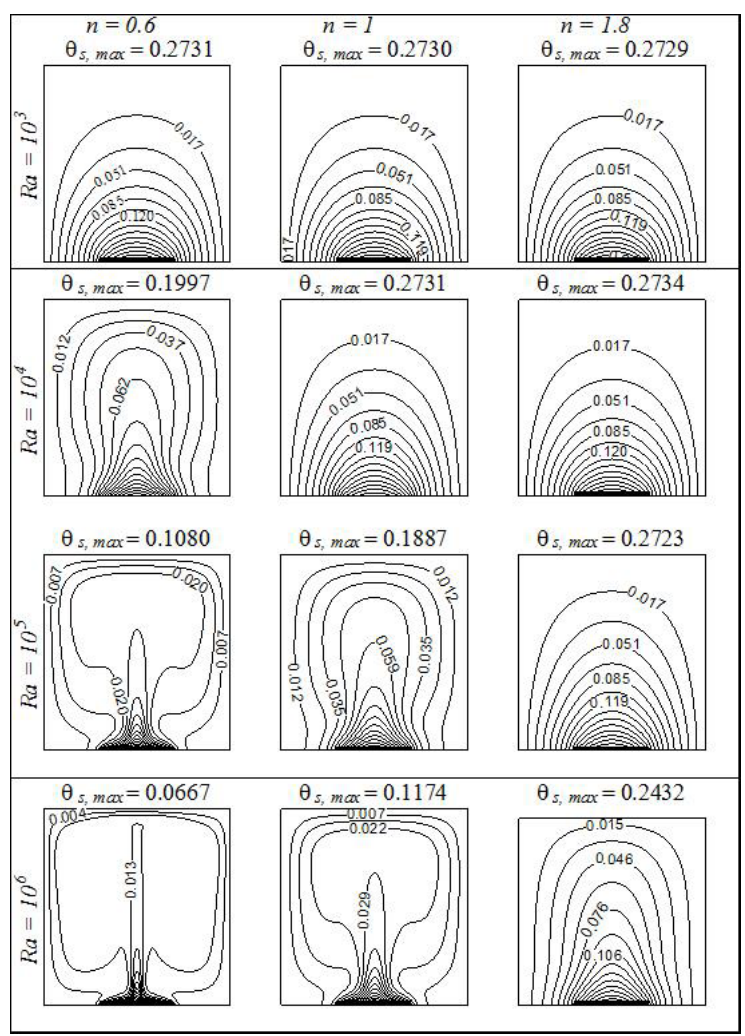

Fig. 6. Isotherms at different Rayleigh numbers and power-law indexes $(W=0.4, S=0.5, \operatorname{Pr}=100)$ 
conduction heat transfer mechanism. At higher Rayleigh numbers, isotherm lines imply that convection is the dominant heat transfer mechanism. For all Rayleigh numbers, convection is weakened by an increase in the power-law index, thereby increasing the heat source temperature, while an increased Rayleigh number reduces the heat source temperature.

Fig. 7 shows the effect of the power-law index on the dimensionless vertical velocity component at the cavity's mid-section $(Y=0.5)$ for $R a=10^{5}$. With an increase in $n$, the maximum and minimum values of the dimensionless vertical velocity component reduce due to an increase in the apparent viscosity of the fluid and a reduction in the strength of the rotating cells, so that for $n=1.8$, convection is almost damped inside the cavity and fluid velocity tends to zero.

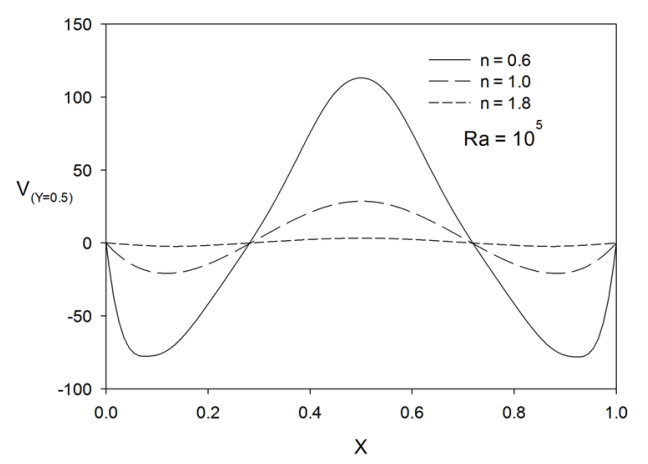

Fig. 7. Vertical velocity profiles along the mid-section of the enclosure for three different power-law indices $(R a=105, W=0.4, S=0.5, \operatorname{Pr}=100)$

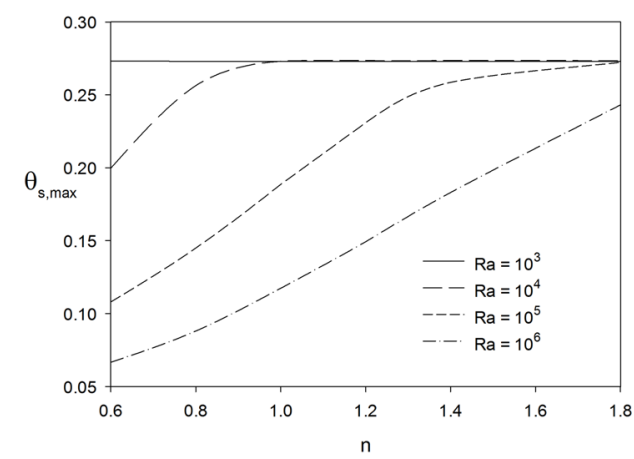

Fig. 8. Variation of heat source maximum temperature versus power-law index at various Rayleigh numbers $(W=0.4, S=0.5, \operatorname{Pr}=100)$

Fig. 8 shows the effects of the Rayleigh number and the power-law index on the maximum dimensionless temperature of the heat source. Since a weak convection is set up inside the cavity at $R a=10^{3}$, the power-law index has only a negligible effect on the maximum temperature of the heat source. At higher Rayleigh numbers, an increased $n$ leads to a weakened natural convection inside the cavity and the fluid takes less heat away from the heat source, thereby increasing the maximum temperature of the heat source. However, an increased Rayleigh number reduces the maximum temperature of the heat source.

Fig. 9 presents the variation of average Nusselt number $\left(N u_{m}\right)$ with the Rayleigh number and the power-law index. At $R a=10^{3}$, where convection inside the cavity is weak, and conduction is the dominant mechanism of heat transfer, the power-law index has no effect on the average Nusselt number. At $R a=10^{4}$, an increased $n$ and weakened convection turn conduction into the dominant mechanism of heat transfer, so that for $n>1$, the average Nusselt number is not affected by changes in $n$. At high Rayleigh numbers $\left(R a=10^{5}, 10^{6}\right)$, the average Nusselt number increases due to an enhanced convection; in these states, an increase in $n$ reduces the average Nusselt number significantly.

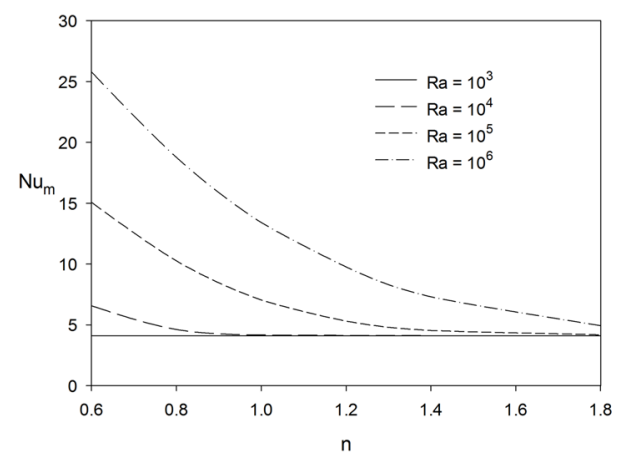

Fig. 9. Variation of average Nusselt number versus power-law index at various Rayleigh numbers $(W=0.4, S=0.5, \operatorname{Pr}=100)$

For a better understanding of the variations of $N u_{m}$ with $R a$ and the power-law index $(n)$, Table 2 presents the percentage changes in the average Nusselt number of non-Newtonian fluids compared to Newtonian fluids at various Rayleigh numbers.

Table 2. The percentages of average Nusselt number variation for non-Newtonian fluids ( $W=0.4, S=0.5, P r=100$ )

\begin{tabular}{ccccc}
\hline & & $\left(\frac{N u_{m}-N u_{m, n=1}}{N u_{m, n=1}}\right) \times 100$ & \\
\hline$R a$ & $10^{3}$ & $10^{4}$ & $10^{5}$ & $10^{6}$ \\
\hline$n=0.6$ & 0.02 & 57.2 & 114.3 & 92.44 \\
\hline$n=0.8$ & 0 & 10.6 & 45.67 & 40.03 \\
\hline$n=1.2$ & -0.01 & -0.96 & -24.68 & -27.26 \\
\hline$n=1.4$ & -0.01 & -1.31 & -35.63 & -45.41 \\
\hline$n=1.8$ & -0.02 & -1.54 & -40.67 & -63.28 \\
\hline
\end{tabular}


In $R a=10^{3}$, the percentage of changes in the average Nusselt number is negligible in nonNewtonian fluids compared to Newtonian fluids. In general, the percentage of changes in the average Nusselt number is positive for shear-thinning nonNewtonian fluids $(n<1)$ and negative for shearthickening non-Newtonian fluids $(n>1)$ compared to Newtonian fluids. At increased Rayleigh numbers and an enhanced convection inside the cavity, the percentage of changes in the average Nusselt number increases in non-Newtonian fluids compared to in Newtonian fluids. The percentage of changes in the average Nusselt number is highest for shear-thinning fluids compared to Newtonian fluids at $R a=10^{5}$, mainly because the dominant mechanism of heat transfer changes from conduction to convection at this $R a$ value and the reduction in viscosity has the most significant enhancing effect on convection.

\subsection{The Effects of the Heat Source Length}

In this section, the power-law index and the position of the heat source were taken as constant and equal to $n=0.6$ and $S=0.5$, and the effects of the heat source length $(0.2 \leq W \leq 0.8)$ on the flow and temperature fields and thermal performance of the cavity were then investigated.

Fig. 10 presents the streamlines (left) and the isotherms (right) at $R a=10^{5}$ for various lengths of the heat source. The strength of the rotating cells is increased due to the greater heat generated by the heat source's increased length. The isotherms indicate that convection is the dominant mechanism of heat transfer. Although convection is boosted with the increase in the length of the heat source, the maximum heat source temperature has not been reduced. In contrast, since a greater heat is generated in the heat source by the increase in its length, the heat source temperature has also increased.

Fig. 11 shows the effects of the Rayleigh number and the length of the heat source on the average Nusselt number $\left(\mathrm{Nu}_{m}\right)$ and the maximum temperature of the heat source. As expected, the average Nusselt number increases with an increase in the Rayleigh number and the subsequently enhanced convection. The average Nusselt number decreases slightly with the increase in the length of the heat source. When the length of the heat source increases, the fluid is in contact with the heat source for a prolonged period, thereby leading to an increase in fluid temperature and a reduction in the temperature gradient next to the heat source. As a result, $N u_{m}$ decreases slightly with the increase in the length of the heat source and despite

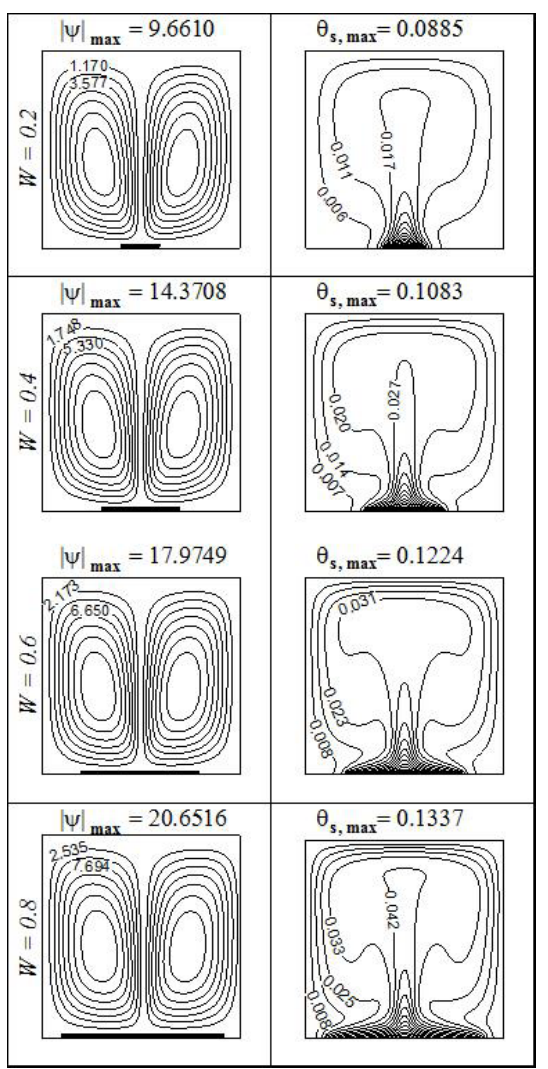

Fig. 10. Streamlines (left) and isotherms (right) for different heat source lengths $(\operatorname{Ra}=105, n=0.6, S=0.5, \operatorname{Pr}=100)$

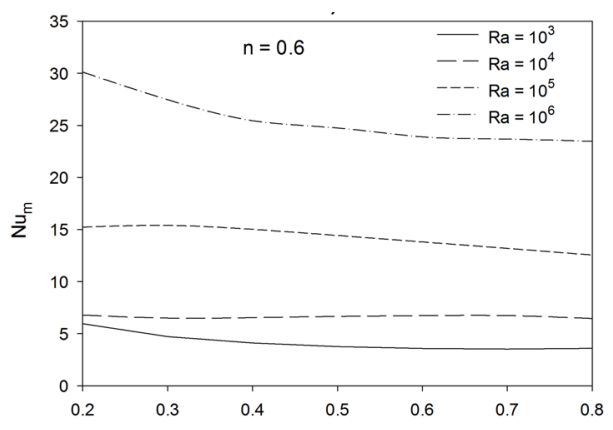

a)

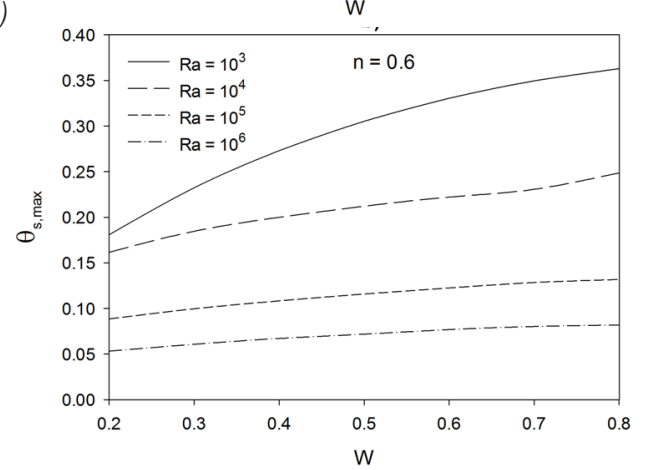

Fig. 11. Effect of heat source length and Rayleigh number on; a) average Nusselt number; and $b$ ) heat source maximum temperature $(n=0.6, S=0.5, \operatorname{Pr}=100)$ 
the enhanced convection. The reduction in the average Nusselt number reduces the cooling power of the fluid; as a result, the maximum temperature of the heat source increases with the length of the heat source. The increase in the maximum temperature of the heat source occurs with greater intensity at $R a=10^{3}$, as at this Rayleigh number, heat is transferred through conduction, and an increase in the length of the heat source leads to the generation of more heat, which then has to be let out by conduction.

\subsection{Effects of the Positioning of the Heat Source}

In this section, the Rayleigh number is taken as $R a=10^{5}$ and the length of the heat source as $W=0.4$, and through changing the position of the heat source $(0.2 \leq S \leq 0.5)$ for three values of the power-law index $(n=0.6,1,1.4)$, the flow and temperature fields and the rate of heat transfer have been examined.

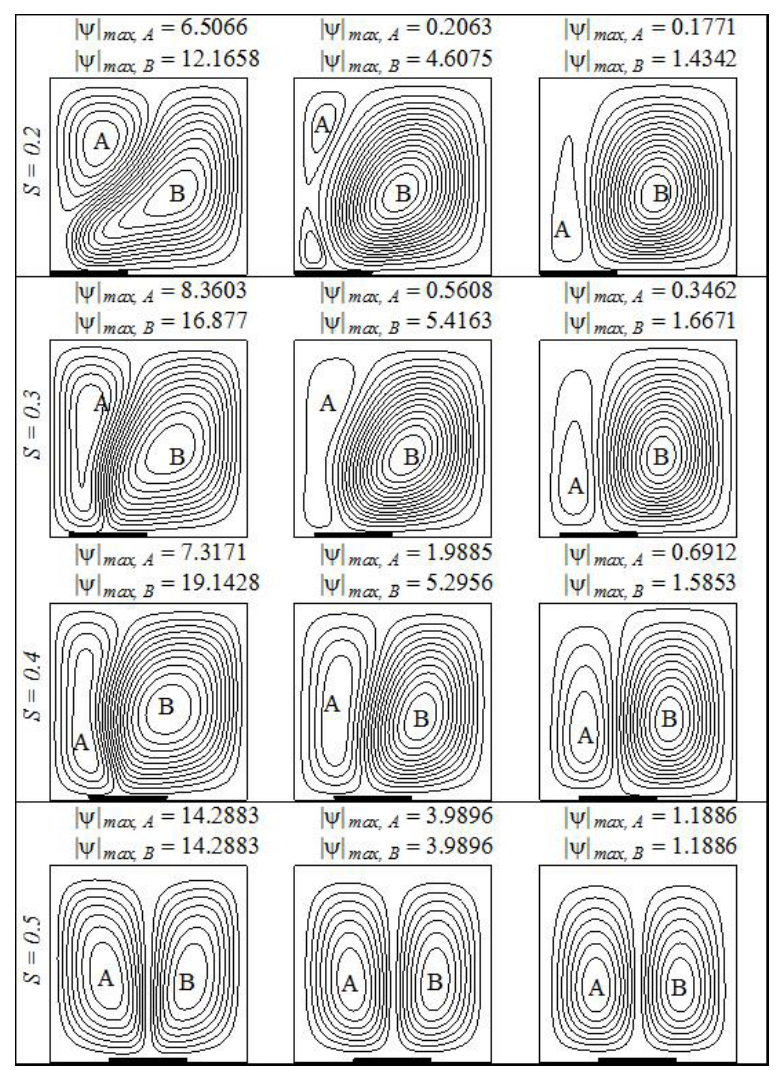

Fig. 12. Streamlines for different locations of the heat source at three different power-law indexes $\left(R a=10^{5}, W=0.4, \operatorname{Pr}=100\right)$

Figs. 12 and 13 show the streamlines and the isotherms for four different positions of the heat source $(S=0.2,0.3,0.4,0.5)$ and three values of $n$. When the heat source is placed next to the cold wall on the left, two asymmetric counter-rotating vortices are formed in the cavity. The strength of the left vortex is lower than the right one due to the limitations of the space in which the fluid rotates and because it is less in contact with the heat source. Through distancing, the heat source from the left wall, the strength of the left vortex increases while the strength of the right vortex decreases following a brief phase of increase. Finally, the strength of both vortices becomes equal when the heat source is in the mid-section of the bottom wall of the cavity.

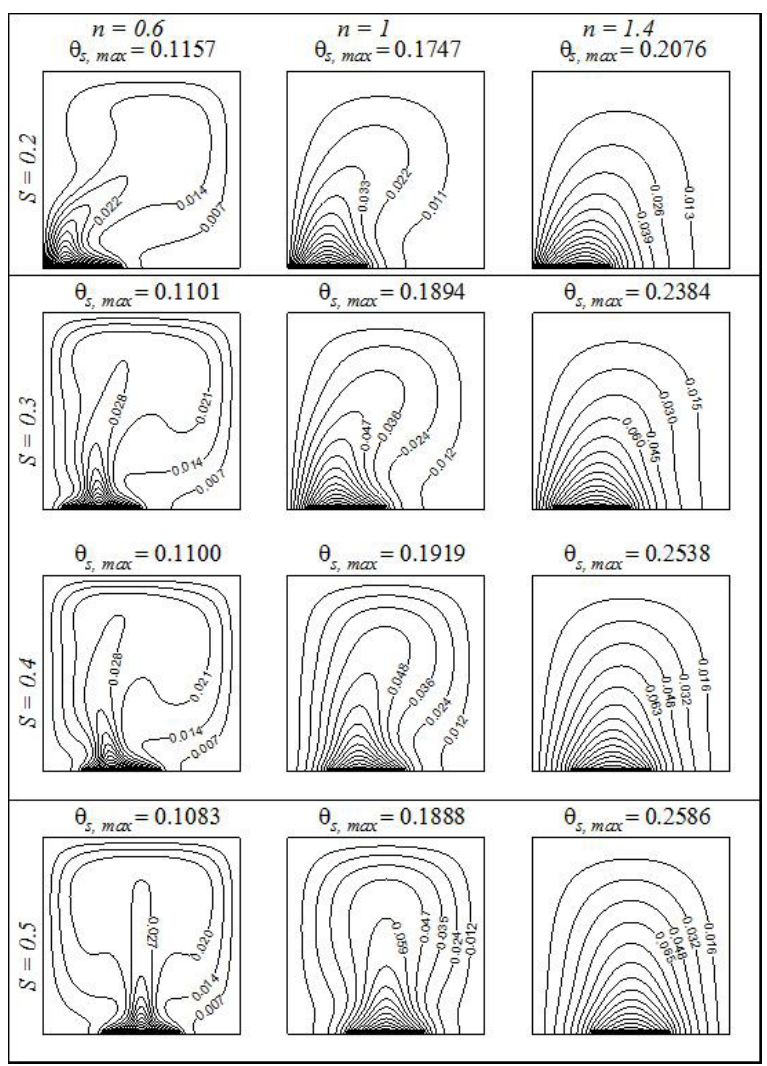

Fig. 13. Isotherms for different locations of the heat source at three different power-law indexes $(R a=105, W=0.4, \operatorname{Pr}=100)$

Isotherms show different behaviours with powerlaw index changes (Fig. 13). At $n=0.6$, isotherms indicate that a considerable convection strength exists inside the cavity for different positions of the heat source and also that convection is the main mechanism for heat transfer. Distancing the heat source from the left wall enhances convection and reduces the maximum temperature of the heat source.

At $n=1$, both conduction and convection mechanisms play a role in heat transfer. By distancing the heat source from the cold left wall, less heat is conducted out and the maximum temperature of 
the heat source, therefore, increases, until the heat source reaches the mid-section of the bottom wall of the cavity, where cold fluid is in contact with the heat source from both sides, thereby reducing the maximum temperature of the heat source. Finally, at $n=1.4$, where conduction is the main mechanism of heat transfer, distancing the heat source from the left wall increases the maximum temperature of the heat source.

Table 3 presents the average Nusselt number for four different positions of the heat source and three values of the power-law index. At $n=0.6$, at which a strong convection is generated inside the cavity, the average Nusselt number does not vary significantly with the position of the heat source. At this state, distancing the heat source from the left wall reduces the average Nusselt number slightly and then, when two vortices with equal strength are formed inside the cavity $(S=0.5)$, the average Nusselt number increases slightly. At $n=1$, where conduction and convection are equally powerful mechanisms for heat transfer, distancing the heat source from the left wall slightly reduces the average Nusselt number at first due to the reduced rate of conduction heat transfer, and when two vortices with equal strength are formed, the average Nusselt number increases. At $n=1.4$, where conduction is the main mechanism of heat transfer, the average Nusselt number decreases with the heat source distancing from the left wall and approaching the mid-section of the bottom wall.

Table 3. Average Nusselt number for different locations of the heat source at three different power-law indexes ( $R a=105, W=0.4$, $\operatorname{Pr}=100)$

\begin{tabular}{lccc}
\hline & \multicolumn{3}{c}{$N u_{m}$} \\
\cline { 2 - 4 } & $n=0.6$ & $n=1$ & $n=1.4$ \\
\hline$S=0.2$ & 14.5487 & 9.3163 & 7.9428 \\
$S=0.3$ & 14.5450 & 7.0014 & 5.0477 \\
$S=0.4$ & 14.5148 & 6.9105 & 4.6306 \\
$S=0.5$ & 14.9846 & 7.0234 & 4.5285 \\
\hline
\end{tabular}

\section{CONCLUSIONS}

This study examines the natural convection in a cavity filled with a non-Newtonian power-law fluid and partially heated from the bottom through a source of uniform heat flux. The effects of the Rayleigh number, the power-law index for non-Newtonian fluids and the length and position of the heat source on the thermal performance of the cavity were investigated. The following conclusions are drawn based on the results obtained.
Increasing the Rayleigh number enhances the natural convection inside the cavity, resulting in a higher rate of heat transfer and a reduced temperature for the heat source. At $n<1$, the natural convection is further enhanced when the Rayleigh number is increased.

Reducing the power-law index (n) reduces the apparent viscosity of the fluid and enhances natural convection inside the cavity, which then leads to an increased rate of heat transfer and a reduced temperature for the heat source. Enhancing natural convection as a result of reducing $n$ is more pronounced at higher Rayleigh numbers.

The average Nusselt number increases for shearthinning and decreases for shear-thickening fluids compared to Newtonian fluids. These changes are more pronounced for shear-thinning fluids $(n<1)$.

Increasing the length of the heat source enhances natural convection inside the cavity, but simultaneously increases the temperature of the heat source and also reduces its average Nusselt number.

When the heat source approaches the mid-section of the bottom wall from the left wall of the cavity, the thermal behaviour of the cavity varies depending on whether the value of the power-law index is greater than, less than or equal to unity.

\section{NOMENCLATURE}

$D_{i j}$ rate of strain tensor $\left[\mathrm{s}^{-1}\right]$

$g$ gravitational acceleration $\left[\mathrm{ms}^{-2}\right]$

$h$ convection heat transfer coefficient $\left[\mathrm{Wm}^{-2} \mathrm{~K}^{-1}\right]$

$k$ thermal conductivity $\left[\mathrm{Wm}^{-1} \mathrm{~K}^{-1}\right]$

$K$ consistency coefficient $\left[\mathrm{Ns}^{n} \mathrm{~m}^{-2}\right]$

$L \quad$ Cavity length $[\mathrm{m}]$

$n$ power-law index [-]

$\mathrm{Nu}$ Nusselt number [-]

$N u_{m}$ average Nusselt number [-]

$p \quad$ fluid pressure $\left[\mathrm{Nm}^{-2}\right]$

$\bar{p} \quad$ modified pressure $\left[\mathrm{Nm}^{-2}\right]$

$P$ dimensionless pressure[-]

$\operatorname{Pr}$ Prandtl number[-]

$q "$ heat flux $\left[\mathrm{Wm}^{-2}\right]$

$R a$ Rayleigh number[-]

$s \quad$ heat source distance from the left wall [m]

$S$ dimensionless distance of heat source from the left wall [-]

$T$ temperature $[\mathrm{K}]$

$u, v$ velocity components in $x, y$ directions $\left[\mathrm{ms}^{-1}\right]$

$U, V$ dimensionless velocity components [-]

$w$ length of the heat source $[\mathrm{m}]$

$W$ dimensionless length of the heat source [-]

$x, y$ Cartesian coordinates [m] 
$X, Y$ dimensionless coordinates[-]

\section{Greek symbols}

$\boldsymbol{\alpha} \quad$ thermal diffusivity $\left[\mathrm{m}^{2} \mathrm{~s}^{-1}\right]$

$\boldsymbol{\beta}$ thermal expansion coefficient $\left[\mathrm{K}^{-1}\right]$

$\Delta T$ reference temperature difference $[\mathrm{K}]$

$\boldsymbol{\tau}_{i j}$ stress tensor[ $\left[\mathrm{Nm}^{-2}\right]$

$\boldsymbol{\theta}$ dimensionless temperature[-]

$\boldsymbol{\mu}$ dynamic viscosity [ $\left.\mathrm{Nsm}^{-2}\right]$

$\boldsymbol{\mu}_{a}{ }^{*}$ dimensionless apparent viscosity [-]

$\boldsymbol{\rho}$ density $\left[\mathrm{kgm}^{-3}\right]$

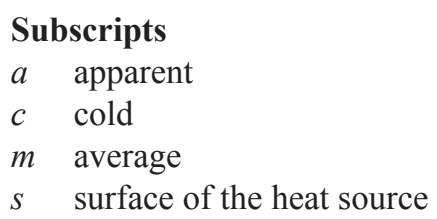

\section{REFERENCES}

[1] Catton, I. (1978). Natural convection in enclosures. Proceedings of the $6^{\text {th }}$ International Heat Transfer Conference, vol. 6, p. 13-31.

[2] De Vahl Davis, G. (1983). Natural convection of air in a square cavity: a bench mark numerical solution. International Journal for Numerical. Methods in Fluids, vol. 3, no. 3, p. 249-264, DOl:10.1002/fld.1650030305.

[3] Ostrach, S. (1988). Natural convection in enclosures. Journal of Heat Transfer, vol. 110, no. 4b, p. 1175-1190, DOI:10.1115/1.3250619.

[4] Bejan, A. (2004). Convection Heat Transfer, 3rd ed. John Wiley, New York.

[5] Emery, A.F., Lee, J.W. (1999). The effects of property variations on natural convection in a square cavity. Journal of Heat Transfer, vol. 121, no. 1, p. 57-62, Dol:10.1115/1.2825966.

[6] Aydın, O., Ünal, A., Ayhan, T. (1999). Natural convection in rectangular enclosures heated from one side and cooled from above. International Journal of Heat and Mass Transfer, vol. 42, no. 13, p. 2345-2355, D0l:10.1016/S00179310(98)00319-6.

[7] Turan, 0., Poole, R.J., Chakraborty, N. (2012). Influences of boundary conditions on laminar natural convection in rectangular enclosures with differentially heated side walls. International Journal of Heat and Fluid Flow, vol. 33, no. 1, p. 131-146, D0I:10.1016/j.jijheatfluidflow.2011.10.009.

[8] Ganguli, A.A., Pandit, A.B., Joshi, J.B. (2009). CFD simulation of heat transfer in a two dimensional vertical enclosure. Chemical Engineering Research and Design, vol. 87, no. 5, p. 711-727, D0I:10.1016/j.cherd.2008.11.005.

[9] Arpino, F., Cortellessa, G., Dell'Isola, M., Massarotti, N., Mauro, A. (2014). High order explicit solutions for the transient natural convection of incompressible fluids in tall cavities. Numerical Heat Transfer, Part A-Application: An International Journal of Computation and Methodology, vol. 66, no. 8, p. 839-862, DOI:10.1080/10407782.2014.892389.

[10] Arpino, F., Cortellessa, G., Mauro, A. (2015). Transient thermal analysis of natural convection in porous and partially porous cavities. Numerical Heat Transfer, Part A-Application: An International Journal of Computation and Methodology, vol. 67, no. 6, p. 605-631, D0l:10.1080/10407782.2014.949133.

[11] Ozoe, H., Churchill, S.W. (1972). Hydrodynamic stability and natural convection in Ostwald-de Waele and Ellis fluids: The development of a numerical solution. AlChE Journal, vol. 18, no. 6, p. 1196-1207, D0l:10.1002/aic.690180617.

[12] Kaddiri, M., Naïmi, M., Raji, A., Hasnaoui, M. (2012). RayleighBenard convection of non-Newtonian power-law fluids with temperature-dependent viscosity. ISRN Thermodynamics, vol. 2012, Article ID 614712, D0I:10.5402/2012/614712.

[13] Kim, G.B., Hyun, J.M., Kwak, H.S. (2003). Transient buoyant convection of a power-law non-Newtonian fluid in an enclosure. International Journal of Heat and Mass Transfer, vol. 46, no. 19, p. 3605-3617, D0I:10.1016/S0017-9310(03)00149-2.

[14] Lamsaadi, M., Naïmi, M., Hasnaoui, M. (2006). Natural convection heat transfer in shallow horizontal rectangular enclosures uniformly heated from the side and filled with non-Newtonian power law fluids. Energy Conversion and Management, vol. 47, no. 15-16, p. 2535-2551, D0I:10.1016/J.enconman.2005.10.028.

[15] Lamsaadi, M., Naïmi, M., Hasnaoui, M., Mamou, M. (2006). Natural convection in a tilted rectangularslot containing nonNewtonian power-law fluids and subject to a longitudinal thermal gradient. Numerical Heat Transfer, Part A: Application: An International Journal of Computation and Methodology, vol. 50, no. 6, p. 561-583, DOI:10.1080/10407780600599513.

[16] Turan, O., Sachdeva, A., Chakraborty, N., Poole, R.J. (2011). Laminar natural convection of power-law fluids in a square enclosure with differentially heated side walls subjected to constant temperatures. Journal of Non-Newtonian Fluid Mechanics, vol. 166, no. 17-18, p. 1049-1063, D0l:10.1016/j. jnnfm.2011.06.003.

[17] Ternik, P., Rudolf, R. (2013). Laminar natural convection of non-Newtonian nanofluid in a square enclosure whit differentially heated side walls. International Journal of Simulation Modeling, vol. 12, no. 1, p. 5-16, D0l:10.2507/ IJSIMM12(1)1.215.

[18] Turan, O., Sachdeva, A., Poole, R.J., Chakraborty, N. (2013). Aspect ratio and boundary conditions effects on laminar natural convection of power-law fluids in a rectangular enclosure with differentially heated side walls. International Journal of Heat and Mass Transfer, vol. 60, p. 722-738, D0I:10.1016/j.ijheatmasstransfer.2013.01.017.

[19] Ternik, P., Buchmeister, J. (2015). Buoyacy-induced flow and heat transfer of power law fluids in a side heated square cavity. International Journal of Simulation Modelling, vol. 14, no. 2, p. 238-249, DOI:10.2507/IJSIMM14(2)5.293.

[20] Alloui, Z., Vasseur, P. (2015). Natural convection of Carreau-Yasuda non-Newtonian fluids in a vertical cavity heated from the sides. International Journal of Heat and Mass Transfer, vol. 84, p. 912-924, D0l:10.1016/j. ijheatmasstransfer.2015.01.092.

[21] Lamsaadi, M., Naïmi, M., Hasnaoui, M. (2005). Natural convection of non-Newtonian power law fluids in a shallow horizontal rectangular cavity uniformly heated from below, Heat and Mass Transfer, vol. 41, no. 3, p. 239-249, DOI:10.1007/s00231-004-0530-8. 
[22] Ouertatani, N., Ben Cheikh, N., Ben Beya, B., Lili, T. (2008). Numerical simulation of two-dimensional Rayleigh-Bénard convection in an enclosure. Comptes Rendus Mécanique, vol. 336, no. 5, p. 464-470, D0l:10.1016/j.crme.2008.02.004.

[23] Khadangi Mahrood, M.R., Etemad, S. G., Bagheri, R. (2011). Free convection heat transfer of non Newtonian nanofluids under constant heat flux condition. International Communications in Heat and Mass Transfer, vol. 38, no. 10, p. 1449-1454, D0I:10.1016/j.icheatmasstransfer.2011.08.012.

[24] Khezzar, L., Siginer, D., Vinogradov, I. (2012). Natural convection of power law fluids in inclined cavities. International Journal of Thermal Sciences, vol. 53, p. 8-17, D0l:10.1016/j. ijthermalsci.2011.10.020.

[25] Alloui, Z., Ben Khelifa, N., Beji, H., Vasseur, P., Guizani, A. (2013).The onset of convection of power-law fluids in a shallow cavity heated from below by a constant heat flux. Journal of Non-Newtonian Fluid Mechanics, vol. 196, p. 70-82, DOI:10.1016/j.jnnfm.2013.01.008.

[26] Turan, O., Lai, J., Poole, R.J., Chakraborty, N. (2013). Laminar natural convection of power-law fluids in a square enclosure submitted from below to a uniform heat flux density. Journal of Non-Newtonian Fluid Mechanics, vol. 199, p. 80-95, DOl:10.1016/j.jnnfm.2013.06.002.

[27] Yigit, S., Poole, R.J., Chakraborty, N. (2015). Effects of aspect ratio on natural convection of Bingham fluids in rectangular enclosures with differentially heated horizontal walls heated from below. International Journal of Heat and Mass Transfer, vol. 80, p. 727-736, D0l:10.1016/j. ijheatmasstransfer.2014.09.046.

[28] Vinogradov, I., Khezzar, L., Siginer, D. (2011). Heat transfer of non-Newtonian dilatant power law fluids in square and rectangular cavities. Journal of Applied Fluid Mechanics, vol. 4, no. 2, p. 37-42.

[29] Anderson, H.l., Irgens, F. (1990). Film Flow of Power-Law Fluids, Cheremisinoff, N.P. (ed.) Encyclopedia of Fluid Mecchanics, Polymer Flow Engineering, vol. 9. Gulf Publishing Company, Houston.

[30] Patankar, S. (1990). Numerical Heat Transfer and Fluid Flow. Mc Graw Hill Book Company, New York. 